\title{
Corrigendum: Ectopic Expression of the Grape Hyacinth (Muscari armeniacum) R2R3-MYB Transcription Factor Gene, MaAN2, Induces Anthocyanin Accumulation in Tobacco
}

\section{OPEN ACCESS}

Edited and reviewed by:

Kevin Davies,

Plant and Food Research

New Zealand

*Correspondence:

Qian Lou

louqian@nwsuaf.edu.cn

Yali Liu

lyl6151@126.com

${ }^{\dagger}$ These authors have contributed equally to this work.

Specialty section:

This article was submitted to Plant Metabolism and Chemodiversity,

a section of the journal

Frontiers in Plant Science

Received: 07 September 2017 Accepted: 20 September 2017

Published: 29 September 2017

Citation:

Chen K, Liu H, Lou Q and Liu Y (2017) Corrigendum: Ectopic Expression of the Grape Hyacinth (Muscari armeniacum) R2R3-MYB Transcription Factor Gene, MaAN2, Induces Anthocyanin Accumulation in Tobacco. Front. Plant Sci. 8:1722. doi: 10.3389/fpls.2017.01722
Kaili Chen ${ }^{1,2 \dagger}$, Hongli Liu ${ }^{1,2+}$, Qian Lou ${ }^{2,3 *}$ and Yali Liu ${ }^{1,3 *}$

${ }^{1}$ College of Landscape Architecture and Arts, Northwest A\&F University, Yangling, China, ${ }^{2}$ State Key Laboratory of Crop Stress Biology in Arid Areas, Northwest A\&F University, Yangling, China, ${ }^{3}$ College of Horticulture, Northwest A\&F University, Yangling, China

Keywords: flower color, monocots, grape hyacinth, R2R3-MYB transcription factor, anthocyanin biosynthesis

\section{A corrigendum on}

Ectopic Expression of the Grape Hyacinth (Muscari armeniacum) R2R3-MYB Transcription Factor Gene, MaAN2, Induces Anthocyanin Accumulation in Tobacco

by Chen, K., Liu, H., Lou, Q., and Liu, Y. (2017). Front. Plant Sci. 8:965. doi: 10.3389/fpls.2017.00965

There is an error in the Acknowledgments section. The correct number for National Natural Science Foundation of China is 31471905.

In the original article, there was an omission in Figure 5 as published. There were 3 missing images for chloroplast autofluorescence. The corrected Figure 5 appears below.

In the original article, there was an omission and error in the legend for Figure $\mathbf{5}$ as published. The missing information was "Autofluorescence: chloroplast autofluorescence," and "Merge is digital image merged with bright field and fluorescent images." should be changed into "Merge is merged with chloroplast autofluorescence, YFP fluorescence, and bright field images." The correct legend appears below.

The authors apologize for these errors and state that this does not change the scientific conclusions of the article in any way.

Conflict of Interest Statement: The authors declare that the research was conducted in the absence of any commercial or financial relationships that could be construed as a potential conflict of interest.

Copyright ( 12017 Chen, Liu, Lou and Liu. This is an open-access article distributed under the terms of the Creative Commons Attribution License (CC BY). The use, distribution or reproduction in other forums is permitted, provided the original author(s) or licensor are credited and that the original publication in this journal is cited, in accordance with accepted academic practice. No use, distribution or reproduction is permitted which does not comply with these terms. 


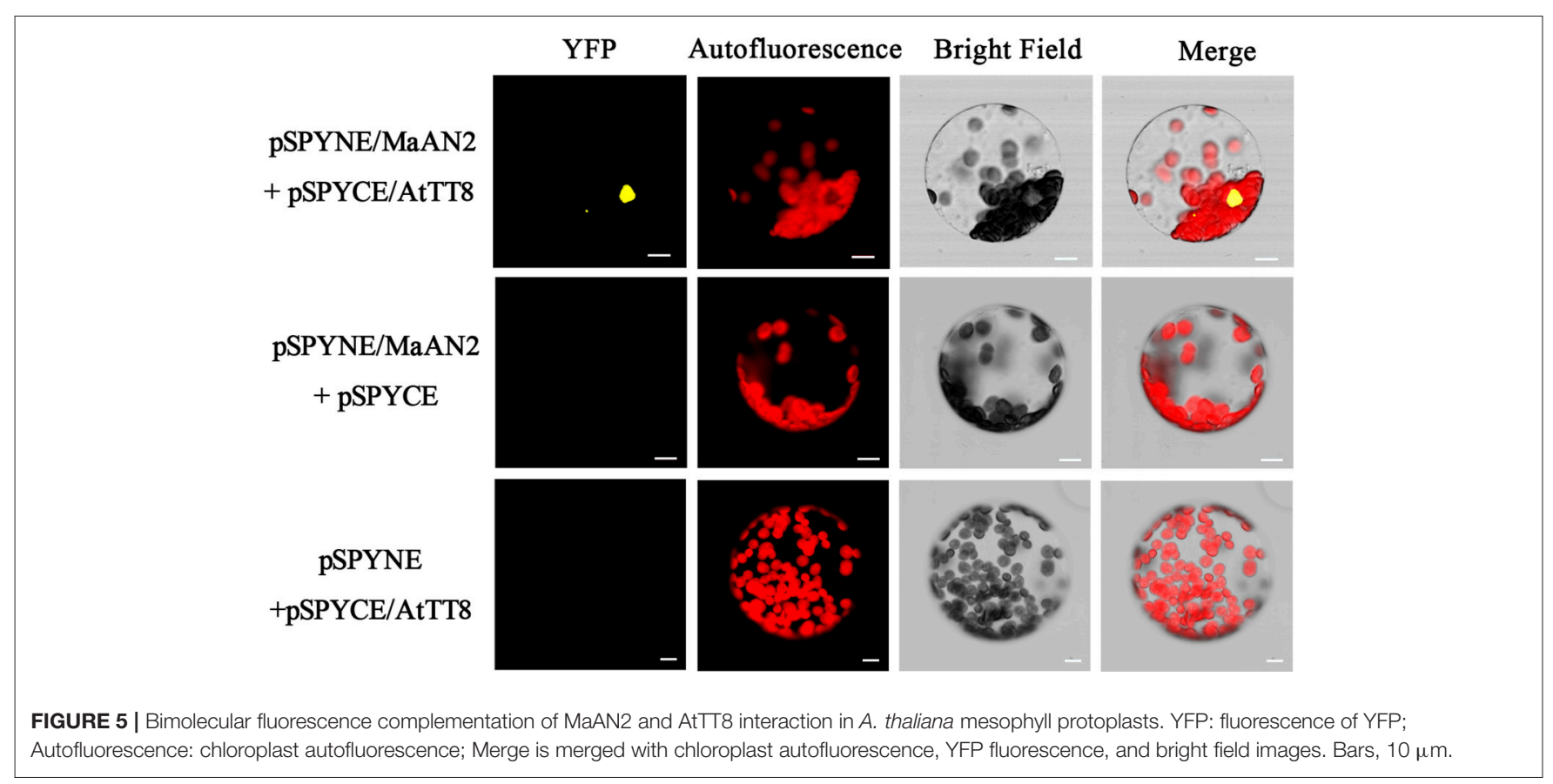

